\title{
Genetic Diversity and Vegetative Compatibility of Fusarium solani Species Complex of Strawberry in Spain
}

\author{
Eduardo De la Lastra, ${ }^{1}$ María Villarino, ${ }^{2}$ Juan Diego Astacio, ${ }^{1}$ Inmaculada Larena, ${ }^{2}$ Antonieta De Cal, ${ }^{2}$ \\ and Nieves Capote ${ }^{1, \dagger}$ \\ ${ }^{1}$ IFAPA Centro Las Torres, 41200 Alcalá del Río, Sevilla, Spain \\ ${ }^{2}$ Department of Plant Protection, Instituto Nacional de Investigación y Tecnología Agraria y Alimentaria, 28040 Madrid, Spain \\ Accepted for publication 25 July 2019.
}

\begin{abstract}
Fusarium solani is a soilborne fungus that is a pathogen to $>100$ plant species. It is the causal agent of crown and root rot in strawberry. We collected $100 \mathrm{~F}$. solani isolates from diseased plants and soils from two distinct geographic areas of strawberry production in Spain: plant nurseries located in the north-central region of the country and fruit production fields located in the southwestern region. The aims of this study were to accurately identify the isolates within the Fusarium solani species complex (FSSC) based on multilocus sequence typing, determine the genetic diversity and population structure of strawberry-associated FSSC based on phylogenetic analysis, and determine the vegetative compatibility among isolates in both strawberry production areas. Seven phylogenetic species, restricted to clade 3 of FSSC, were defined in the Spanish strawberry crops, showing a regional variation of species composition. Isolates from nurseries were composed of four phylogenetic species (i.e., FSSC 2, FSSC 5, FSSC 9, and an unknown FSSC species) that matched with five vegetative compatibility groups (VCGs). Isolates from fruit production fields included five phylogenetic species (i.e., FSSC 2,
\end{abstract}

ABSTRACT

Spain is the number one producer of strawberry (plants and fruit) in the European region (FAOSTAT 2016). Strawberry cultivation in Spain is divided by both cultural methods and geography. The production of plants takes place in high-elevation nurseries in the north-central region of Spain (mainly Segovia and Ávila provinces), where optimal agroclimatic conditions allow an adequate vegetative multiplication of plants (López-Aranda 2008). Plant cultivation is carried out extensively in open sandy fields in a triennial crop rotation mainly with cereal, endive, and carrot. Strawberry runner plants are uprooted or harvested during the months of September and October and transplanted into fruit production fields located mainly in southwestern Spain (Huelva province). Cultivation for fruit production takes place intensively in beds under plastic macro- or microtunnels, with controlled fertilization and irrigation.

†Corresponding author: N. Capote; marian.capote@juntadeandalucia.es

Funding: This work was supported by European Regional Development Fund (ERDF) grant RTA2013-00062-C05-02, with cofinancing from the 2014 to 2020 ERDF "Smart Growth" Operational Programme. E. De la Lastra is supported by a $\mathrm{PhD}$ fellowship from the European Union and the Instituto Nacional de Investigación y Tecnología Agraria y Alimentaria. M. Villarino held postdoctoral contracts that were associated with Instituto Nacional de Investigación y Tecnología Agraria y Alimentaria grant RTA2013-00062-C05-01 from the Ministry of Economy and Competitiveness, Spain.

E. De la Lastra and M. Villarino contributed equally to this work.

*The $\boldsymbol{e}$-Xtra logo stands for "electronic extra" and indicates that one supplementary figure and one supplementary table are published online.

The author(s) declare no conflict of interest.

This article is in the public domain and not copyrightable. It may be freely reprinted with customary crediting of the source. The American Phytopathological Society, 2019.
FSSC $3+4$, FSSC 5, FSSC 6, and FSSC 11) distributed into 29 VCGs not correlated with phylogenetic groups. FSSC 5 and FSSC 2 were the most abundant species in nurseries and fruit production fields, respectively, and they were the only species present in both production areas. Of the 47 sequence-based haplotypes defined, no haplotypes were shared between nurseries and fruit production fields. Pathogenic isolates were present in all but FSSC 6 and FSSC 9 species, and FSSC $3+4$ contained the higher percentage of pathogenic isolates. No relationship was observed between pathogenicity and the source of isolates (plant or soil). Generally, species present in fruit production fields showed higher genetic diversity than those present in nurseries. This work can contribute to understanding the diversity of this species complex in Spanish strawberry production areas, which will be useful for developing integrated disease management strategies.

Keywords: Fusarium multilocus sequence typing, fruit production fields, mycology, nursery, phylogenetic analysis, vegetative compatibility groups
Soil disinfestation is an essential activity for strawberry fruit producers to start from healthy and pathogen-free plants (De Cal et al. 2004). The phase out of chemical soil fumigants used in the European Union, including methyl bromide, in accordance with the Montreal Protocol is a likely cause for the emergence and reemergence of soilborne fungal diseases in the strawberry crop (Martin 2003).

Among soilborne fungal pathogens that affect strawberry crops, Fusarium solani (Mart) Sacc has been described as the causal agent of crown and root rot in strawberry-causing stunted growth, wilting, and/or plant death (Pastrana et al. 2014). The fungus has been detected in plant material and soil from Spanish strawberry nurseries (Redondo et al. 2012) and fruit production fields (Pastrana et al. 2014). F. solani has also been described as a strawberry pathogen in Italy (Manici et al. 2005), Mexico (Ceja-Torres et al. 2008), Iran (Ayoubi and Soleimani 2016), and Pakistan (Mehmood et al. 2017). In addition, metagenomic analysis of strawberry cultivation soils also revealed an abundance of pathogenic F. solani in strawberry fields in Estonia (Mirmajlessi et al. 2018). Studies on the current incidence in Spanish strawberry nurseries and fruit production fields and inoculum density in soils are scarce, because $F$. solani was not described as a strawberry pathogen. Yield losses at the national level have not yet been calculated; however, a negative correlation between inoculum density of $F$. solani in the soil and fruit yield has been described in Spanish fruit production fields (De la Lastra et al. 2018). In addition, the capacity of this fungus to adapt to long-term survival in soil as resistant structures called chlamydospores (Schippers and van Eck 1981), its ability to asymptomatically colonize other plant species that could act as fungal reservoirs (MolineroRuiz et al. 2011; Pastrana et al. 2017), and the introduction of potentially infected runner plants into fruit production fields make $F$. solani a threat to strawberry crops in Spain. 
The fungus $F$. solani is a phylogenetically and biologically complex group known as the $F$. solani species complex (FSSC), which is composed of morphologically indistinguishable saprophytic and pathogenic isolates (Nalim et al. 2011; O'Donnell 2000; O'Donnell et al. 2008; Short et al. 2013; Zhang et al. 2006). Phylogenetic analyses of FSSC have led to the description of three major clades that comprise $>60$ phylogenetic species (O'Donnell 2000). Clade 1 of the FSSC has only two known species: Fusarium illudens and Fusarium plagianthi from New Zealand. Clade 2 comprises at least eight phylogenetic species, including Fusarium viguliforme and Fusarium tucumaniae, the causal agents of soybean sudden death syndrome (Aoki et al. 2003). Clade 3 is the most abundant and diverse group, containing species associated with soils and plants as well as with opportunistic animal and human diseases (Zhang et al. 2006). Several species in this clade have been named; the most common are FSSC 1 (Fusarium petroliphilum), FSSC 2 (Fusarium keratoplasticum), FSSC $3+4$ (Fusarium falciforme), FSSC 5 (F. solani sensu stricto), and FSSC 6 (Fusarium metavorans sp. nov.) (Al-Hatmi et al. 2018; Nalim et al. 2011; Schroers et al. 2016; Short et al. 2013; Summerbell and Schroers 2002). However, the majority of species remain unnamed and are classified by numbering.

A multilocus sequence typing (MLST) database, Fusarium MLST (http://www.westerdijkinstitute.nl/fusarium), with partial sequences from phylogenetically informative loci was developed to facilitate accurate identification of single phylogenetic Fusarium species. For accurate FSSC identification, the analysis of three loci has been suggested: the translation elongation factor$1 \alpha(E F-1 \alpha)$, the internal transcribed spacer (ITS) ribosomal DNA (rDNA) region plus D1 and D2 domains of the nuclear 28S large subunit (LSU), and the second largest subunit of RNA polymerase II (RPB2) (O'Donnell et al. 2008, 2010; Zhang et al. 2006).

FSSC can reproduce both sexually and asexually. In addition, some isolates have the ability to anastomose and fuse their hyphae with each other to form stable heterokaryons, allowing the exchange of genetic information (Leslie 1993; Sugimoto et al. 2003). Isolates that are able to anastomose belong to the same vegetative compatibility group (VCG) (Puhalla 1985). Heterokaryon formation by somatic fusion between individuals can occur independently of sexual reproduction, but generally, it only takes place among strains with similar genotypes. Thus, vegetative compatibility has been used to study the origins and relatedness of isolates among Fusarium species and provides a valuable trait to characterize diversity (Swift et al. 2002).

Estimating the genetic diversity and the population structure of FSSC from the strawberry crop can increase our understanding of the pathogen and improve the management. In addition, the analysis of the genetic diversity could reflect the sequence of migration and spread throughout the strawberry crop, and hence, it could provide information on the source of inoculum of this fungus. Studies on the characterization of $F$. solani isolates from strawberry plants and soil from nurseries and fruit production fields in Spain have revealed considerable variability and differences in morphological and pathogenic characteristics among the isolates in both strawberry production areas (Villarino et al. 2019). In this work, additional characterization of these isolates has been carried out to compare species composition, genetic variability, and vegetative compatibility of FSSC isolates from both production areas. To achieve this, 100 isolates of FSSC were obtained from diseased strawberry plants and soils and a multilocus sequence dataset consisting of concatenated $E F-1 \alpha$, ITS + LSU, and RPB2 partial sequences to identify the strawberry-associated FSSC strains in both strawberry production areas via the Fusarium MLST online database and to assess the genetic diversity and the relationships among isolates by phylogenetic analyses. Additionally, we determined the vegetative compatibility among isolates based on nitrate nonutilizing (nit) mutants.

\section{MATERIALS AND METHODS}

Fungal isolates. FSSC isolates were obtained from strawberry plants from nurseries and fruit production fields during the 2014/ $2015,2015 / 2016$, and 2016/2017 strawberry seasons. Two nurseries were sampled each year in the Navalmanzano and Arévalo localities (Segovia and Ávila provinces, respectively). For each nursery, 20 symptomatic runner plants from the center row of each plot were sampled three times after planting (June, August, and September months) throughout each season, making a total of 60 runner plants per nursery and season. Plant densities in nurseries are about 15,000 plants per 1 ha. Thirteen fruit production fields were sampled each season: 12 located in Huelva (the province with the largest volume of strawberry production in Spain) and 1 located in Cádiz, a province with lower-volume strawberry production. We collected all of the declined or dead plants from each plot of 2,150 plants. Plant crown, root, and petiole segments $(0.5$ to $1 \mathrm{~cm})$ were surface sterilized in $1 \%$ sodium hypochlorite for $2 \mathrm{~min}$, rinsed in sterile distilled water, air dried, placed onto potato dextrose agar (PDA), and incubated at $25^{\circ} \mathrm{C}$ for 2 days in darkness followed by 5 days at a 12-h photoperiod (OSRAM L 18-W/21-840 Hellweiss Lumilux Cool White; $\left.75 \mu \mathrm{E} \mathrm{m}^{-2} \mathrm{~s}^{-1}\right)$.

Additional isolates of FSSC were obtained from nonfumigated soils from the same nurseries and fruit production fields from which plants were sampled. Soil samples in nurseries consisted of 20 random samples per nursery ( 0 - to $20-\mathrm{cm}$ depth) collected at the beginning of the season and pooled in a composite sample. Soil samples in fruit production fields consisted of soil immediately below the collected plants (0- to $20-\mathrm{cm}$ depth). Samples were processed by dilution plating. Soil ( 5 to $10 \mathrm{~g}$ ) was added to a flask containing $150 \mathrm{ml}$ of $0.1 \%$ water-agar and placed on a stir plate for $30 \mathrm{~min}$ at $150 \mathrm{rpm}$. Dilutions (10- to 100 -fold) were made, and $1-\mathrm{ml}$ aliquots from undiluted and diluted suspensions were spread onto petri dishes containing PDA amended with $0.5 \mathrm{~g} \mathrm{liter}^{-1}$ streptomycin and selective media for Fusarium spp. (Nash and Snyder medium; five plates per soil sample); they were incubated at $25^{\circ} \mathrm{C}$ for 2 days in darkness followed by 3 additional days with a 12 -h photoperiod.

Fusarium-like white to pale cream colonies from plant and soil samples were selected after 10 days of incubation. Cultures derived from single spores were subsequently obtained. Morphological characterization was performed by microscopic examination. Unbranched monophialides, microconida, macroconidia, and chlamydospores were consistent with the descriptions of $F$. solani (Martius) Appel \& Wollenweber emend Snyder \& Hansen (Leslie and Summerell 2006). Identification was confirmed by sequencing of a portion of the EF-l $\alpha$ gene using primers EF1 and EF2 (O'Donnell et al. 1998b). Fungal isolates were stored in 20\% (vol/ vol) glycerol at $-80^{\circ} \mathrm{C}$. To compare isolates coming from nurseries and fruit production fields based on species composition, genetic variability, and compatibility groups, 100 isolates were selected for further characterization taken equally from the two production areas. These isolates were previously characterized morphologically and pathogenically by Villarino et al. (2019).

DNA extraction, amplification, and sequencing. DNA was extracted from single-spore cultures of the 100 selected isolates (Supplementary Table S1) using the Isolate II Plant DNA Kit (Bioline) following the manufacturer's instructions with some modifications. Briefly, fungal mycelium grown on PDA was scraped from the plate, placed into a centrifuge tube containing lysis buffer (Bioline), and homogenized with a pistil coupled to an electric drill. The subsequent DNA extraction steps were performed as described in the instruction manual. The DNA concentration was determined on an ND-1000 NanoDrop spectrophotometer (NanoDrop Products).

PCR reactions were performed to amplify and partially sequence three genes of each isolate for MLST: $E F-1 \alpha$, ITS + LSU, and $R P B 2$. For the amplification of the $5^{\prime}$ and $3^{\prime}$ fragments of the $R P B 2$ gene, two pairs of primers were designed by the alignment of partial 
sequences from the FSSC species reported on GenBank using MEGA 7 software (Kumar et al. 2016) and identification of specific consensus sequences (Table 1). PCR reactions contained 10× PCR Buffer (Intron Biotechnology, Inc.), $2 \mathrm{mM} \mathrm{MgCl} 2,0.25 \mathrm{mM}$ each dNTP, $0.4 \mu \mathrm{M}$ each primer (Table 1 ), $1 \mathrm{U}$ of $i$-Pfu DNA polymerase (Intron Biotechnology, Inc.), and 20 to $100 \mathrm{ng}$ of genomic DNA. Amplifications were carried out at $95^{\circ} \mathrm{C}$ for 3 min followed by 35 cycles of $30 \mathrm{~s}$ at $95^{\circ} \mathrm{C}, 20 \mathrm{~s}$ at $59^{\circ} \mathrm{C}$ (for $E F-1 \alpha$ ) or $55^{\circ} \mathrm{C}$ (for ITS + LSU and RPB2), and $30 \mathrm{~s}$ at $72^{\circ} \mathrm{C}$. The size of the amplicons was resolved in $1.5 \%$ agarose gels in $0.5 \times$ TAE (Tris-acetate-EDTA) buffer; then, they were stained with RedSafe nucleic acid staining solution (Intron Biotechnology, Inc.) and visualized over an ultraviolet transilluminator. Amplicons were purified using the FavorPrep Gel/PCR purification kit (Favorgen) following the manufacturer's instructions and sequenced by STAB VIDA DNA Sequencing Service. Sequences were deposited in GenBank and compared with available sequences in GenBank and Fusarium-ID databases by BLAST analysis.

To accurately identify the FSSC isolates present in nursery and fruit production fields, an MLST was performed according to the Fusarium MLST database (http://www.westerdijkinstitute.nl/ fusarium/) using sequences of the three studied loci.

Phylogenetic analysis. Independent and concatenated $E F-1 \alpha$, ITS + LSU, and RPB2 sequence fragments (3,574 nucleotides) were used for the phylogenetic analysis of nursery and fruit production field isolates, including FSSC sequences retrieved from GenBank. In addition, previously characterized (Villarino et al. 2019) pathogenic and nonpathogenic isolates from both production areas were separately analyzed. Multiple sequence alignments were performed in MEGA7 software (Kumar et al. 2016) using the CLUSTALW algorithm (Thompson et al. 1994) refined with MUSCLE (Edgar 2004) and edited manually. Phylogenetic analyses were conducted using MEGA7 through maximum likelihood (ML) analysis using the general time-reversible model (Tavaré 1986) for the analysis of strawberry FSSC and GenBank-retrieved isolates (Fig. 1) or the Tamura and Nei model (Tamura and Nei 1993) for the separate analysis of nursery (Fig. 2) and fruit production field (Fig. 3) isolates, with a rate of variation across sites (Yang 1994) and a proportion of invariable sites (Shoemaker and Fitch 1989) for both models. Support for internal branches was assessed by 1,000 ML bootstrapped pseudoreplicates of data. Nodes with bootstrap support $>70 \%$ were indicated in the final trees.

Genetic diversity. Haplotype distribution of the isolates was performed by DnaSP v5 software (Librado and Rozas 2009). Number of haplotypes (h), haplotype (or gene) diversity $(\mathrm{H})$, and nucleotide diversity $(\pi)$ of the FSSC species defined were calculated using DnaSP v5. A haplotype is defined as a particular sequence (i.e., two individuals have different haplotypes if their sequences differ in one or more nucleotides). Haplotype diversity measures the singularity of a haplotype in a given population in relation to sample size, and it is based on the frequency of each haplotype in a given population. Nucleotide diversity is used to measure the degree of polymorphism in a population based on the average number of nucleotide differences among DNA sequences in the population
(Nei 1987). To examine a possible exchange of genetic information among isolates from nurseries and fruit production fields via runner plants, genetic diversity between populations (Dxy) in the nursery and the fruit production field were calculated for the only two species present in both production areas (i.e., FSSC 2 and FSSC 5) using DNA sequence information from concatenated loci. Dxy (Nei 1987) measures the extent of DNA divergence between populations considering the effect of DNA polymorphisms. It is calculated as the average number of nucleotide substitutions per site between populations. In addition, for these two species FSSC 2 and FSSC 5, genetic differentiation parameters (sequence-based statistic for genetic differentiation [Fst] and nearest neighbor statistic for genetic differentiation [Snn]) and the inferred gene flow (Nm) between nursery and fruit production fields were estimated by DnaSP v5 software. Fst (Hudson et al. 1992) is a sequence-based statistic that uses the information on the number of differences between sequences within and among preassigned populations. Values of Fst range from zero (complete panmixia) to one (completely distinct populations). $\mathrm{Nm}$ is an estimation of the gene flow between populations, which is a measure of the exchange of genetic information among populations via migration of individuals, where $\mathrm{N}$ is the size of the population and $m$ is the migration rate. Gene flow is detected when $N>1$, and it is not detected when $\mathrm{N}<1$. Snn is a measure of how often the most similar sequence is found in the same preassigned population (Hudson 2000). Values of Snn range from 0.5 to 1 . Snn is expected to be near 1 when the populations at the two localities are highly differentiated and near 0.5 when the population is panmictic. Significance of Snn value was computed by permutation (randomization) test (Hudson et al. 1992).

VCGs. Vegetative compatibility tests were assessed in FSSC isolates from nurseries and fruit production fields using nitrate nit mutants as described by Jacobson and Gordon (1988). nit 1/3 and nit $\mathrm{M}$ mutants were obtained by culturing wild-type isolates on PDA amended with 4 to $6 \%$ potassium chlorate at $25^{\circ} \mathrm{C}$ with a 12 -h photoperiod for 7 to 10 days. The fast-growing sectors of the fungus that are believed to be chlorate resistant were transferred in parallel to plates containing Czapek agar $(\mathrm{CZ})$ and $\mathrm{CZ}+2 \%$ hypoxanthine, respectively. Colonies with flat growth and hyaline mycelium on $\mathrm{CZ}$ plates and wild-type growth on $\mathrm{CZ}+$ hypoxanthine plates were identified as nit $1 / 3$ mutants. Colonies with flat growth and hyaline mycelium on both $\mathrm{CZ}$ and $\mathrm{CZ}+$ hypoxanthine media were identified as nit $\mathrm{M}$ mutants. nit 1/3 mutants were obtained for all isolates. nit $\mathrm{M}$ mutants were also obtained for each VCG group and used as testers. nit 1/3 mutants obtained from all studied isolates were paired with the nit $\mathrm{M}$ testers (including the one belonging to its own VCG as a control) on CZ plates. If wild-type growth mycelium develops along the line of contact between the nit $1 / 3$ and nit $\mathrm{M}$ isolates, anastomosis has occurred, and hence, that isolate was assigned to the VCG represented by the nit $\mathrm{M}$ isolate. The absence of wild-type growth indicated that the nit 1/3 isolate was not compatible with the nit $\mathrm{M}$ strain (Jacobson and Gordon 1988). This process was continued until all isolates were associated with a VCG. If a nit $1 / 3$ isolate was not compatible with any other nit $\mathrm{M}$ strain, it was paired with its own nit $\mathrm{M}$ mutant to discard self-incompatibility and assigned a unique VCG.

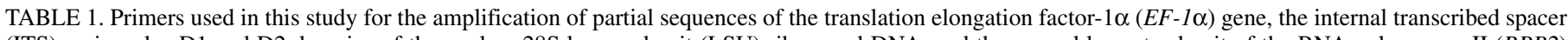

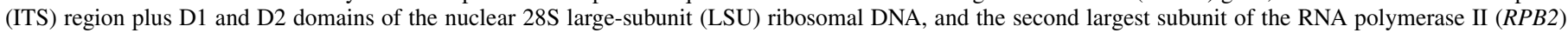
gene of Fusarium solani species complex isolates from strawberry crops

\begin{tabular}{|c|c|c|c|c|}
\hline Primer & Sequence $\left(5^{\prime}\right.$ to $\left.3^{\prime}\right)$ & Locus & Length (bp) & Ref. \\
\hline ef1 & ATGGGTAAGGARGACAAGAC & $E F-1 \alpha$ & 666 & O'Donnell et al. (1998a) \\
\hline ef2 & GGARGTACCAGTSATCATGTT & & & O'Donnell et al. (1998a) \\
\hline Fs-RPB2-5F & GGGGAGACCAGAAGAAGGC & $R B P 2$ (5' region) & 864 & This work \\
\hline Fs-RPB2-5R & CCCATGGCCTGTTTACCCAT & & & This work \\
\hline Fs-RPB2-3F & GCCCATGATTCAACGTGATGC & $R B P 2$ ( $3^{\prime}$ region $)$ & 960 & This work \\
\hline Fs-RPB2-3R & CGAAGCTTGCGTCCAGTATG & & & This work \\
\hline ITS5 & GGAAGTAAAAGTCGTAACAAGG & ITS + LSU & 1,084 & White et al. (1990) \\
\hline NL4 & GGTCCGTGTTTCAAGACGG & & & O’Donnell et al. (2010) \\
\hline
\end{tabular}




\section{RESULTS}

Identification of FSSC species associated with the strawberry crop. Fifty FSSC isolates were obtained from Spanish strawberry nurseries (29 from soil and 21 from strawberry plants), and 50 isolates were selected from Spanish fruit production fields (25 from soil and 25 from strawberry plants), including previously characterized pathogenic and nonpathogenic isolates (Villarino et al. 2019). The partial EF-l $\alpha$, ITS + LSU rDNA, and RPB2 sequences used for the MLST of the isolates consisted of 666, 1,084 , and 1,824 base pairs, respectively, totaling 3,574 base pairs of aligned DNA sequence per isolate. Phylogenetic analyses of the 100 isolates along with representatives of the known FSSC clades 1,2, and 3 species strongly supported that all of the strawberry-associated isolates were restricted to clade 3 of FSSC (Fig. 1).

MLST and phylogenetic analysis defined seven phylogenetic species within the FSSC in the Spanish strawberry crop: that is, FSSC 5 (the most abundant species; named $F$. solani sensu stricto;
$45 \%$ of all isolates), FSSC 2 (named F. keratoplasticum; 29\%), FSSC $3+4$ (named F. falciforme; $12 \%$ ), FSSC 6 (named F. metavorans sp. nov.; 6\%), and the unnamed phylogenetic species FSSC $9(1 \%)$ and FSSC $11(1 \%)$. An unknown species (6\% of all isolates) was also detected in nurseries and strongly supported by individual and multilocus phylogenetic analyses (99\% bootstrap by $E F-1 \alpha$ and $R P B 2,98 \%$ bootstrap by ITS + LSU [data not shown], and $91 \%$ bootstrap by multilocus) (Fig. 1). There was a regional variation of species composition. The most abundant species, FSSC 5 and FSSC 2, were present in both strawberry areas at different frequencies: FSSC 5 was the most abundant in nurseries (76\%), and FSSC 2 was the most abundant in fruit production fields (48\%). The rest of the species were exclusively from nurseries (FSSC 9 and the unknown FSSC) (Fig. 2) or fruit production fields (FSSC $3+4$, FSSC 6, and FSSC 11) (Fig. 3).

FSSC 2, FSSC $3+4$, FSSC 5, and the unknown FSSC species contained pathogenic and nonpathogenic isolates from plant and soil origins. FSSC 6 and FSSC 9 were composed of nonpathogenic isolates from soil, and FSSC 11 was formed by a single pathogenic

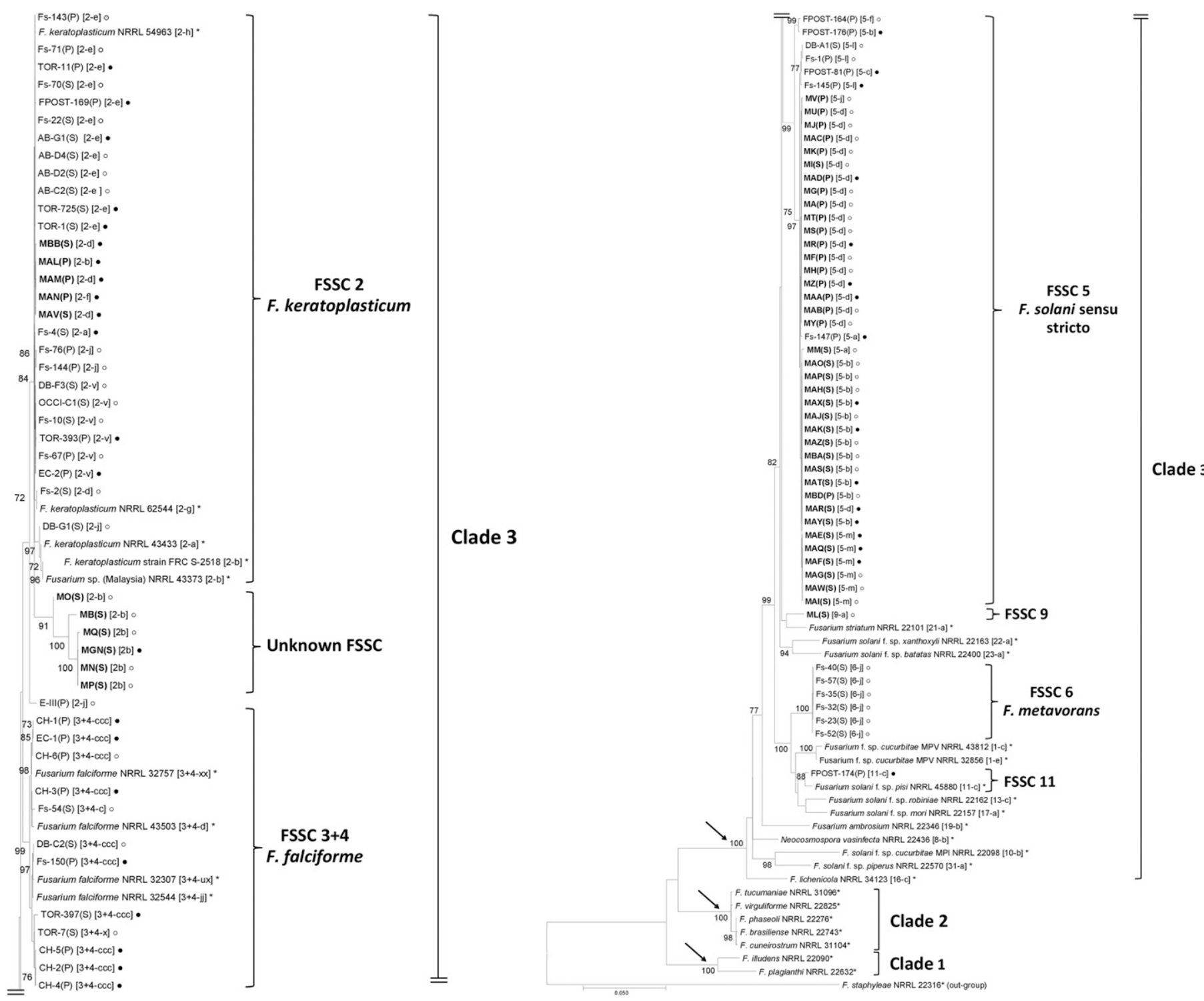

Fig. 1. Phylogenetic diversity of Fusarium solani species complex (FSSC) isolates from soil (S) and strawberry plants (P) of Spanish strawberry nurseries (bold) and fruit production fields (not bold) using maximum likelihood analysis of the concatenated elongation factor-1 $\alpha$ (666 base pairs), internal transcribed spacer + large subunit (1,084 base pairs), and RNA polymerase II (1,824 base pairs) sequence data. Fusarium staphylae NRRL 22316 was used as an outgroup. Support values are above branches and represent bootstrap values of $\geq 70 \%$. Haplotypes defined by the Fusarium multilocus sequence typing database appear in brackets. Arrows indicate the bootstrap support of the three clades described in the FSSC. ๑, Pathogenic isolates; $\bigcirc$, nonpathogenic isolates. *Sequences retrieved from GenBank. 
isolate from plant origin. Among the FSSC species containing pathogenic isolates, FSSC $3+4$ from fruit production fields showed the highest percentage of pathogenic isolates $(67 \%)$ followed by FSSC 2 (46\%), FSSC 5 (37\%), the unknown FSSC (17\%), and FSSC 11 (a single pathogenic isolate) (Fig. 1 and Supplementary Fig. S1).
The pathogenic species detected in nurseries were FSSC 2, FSSC 5 , and the unknown FSSC, which contained 100, 32, and $20 \%$ of pathogenic isolates, respectively. Pathogenic nursery isolates within FSSC 2 and FSSC 5 species came from both soil and plant sources, and the unknown FSSC pathogenic isolate was from soil origin. The only FSSC 9 nursery isolate was nonpathogenic to

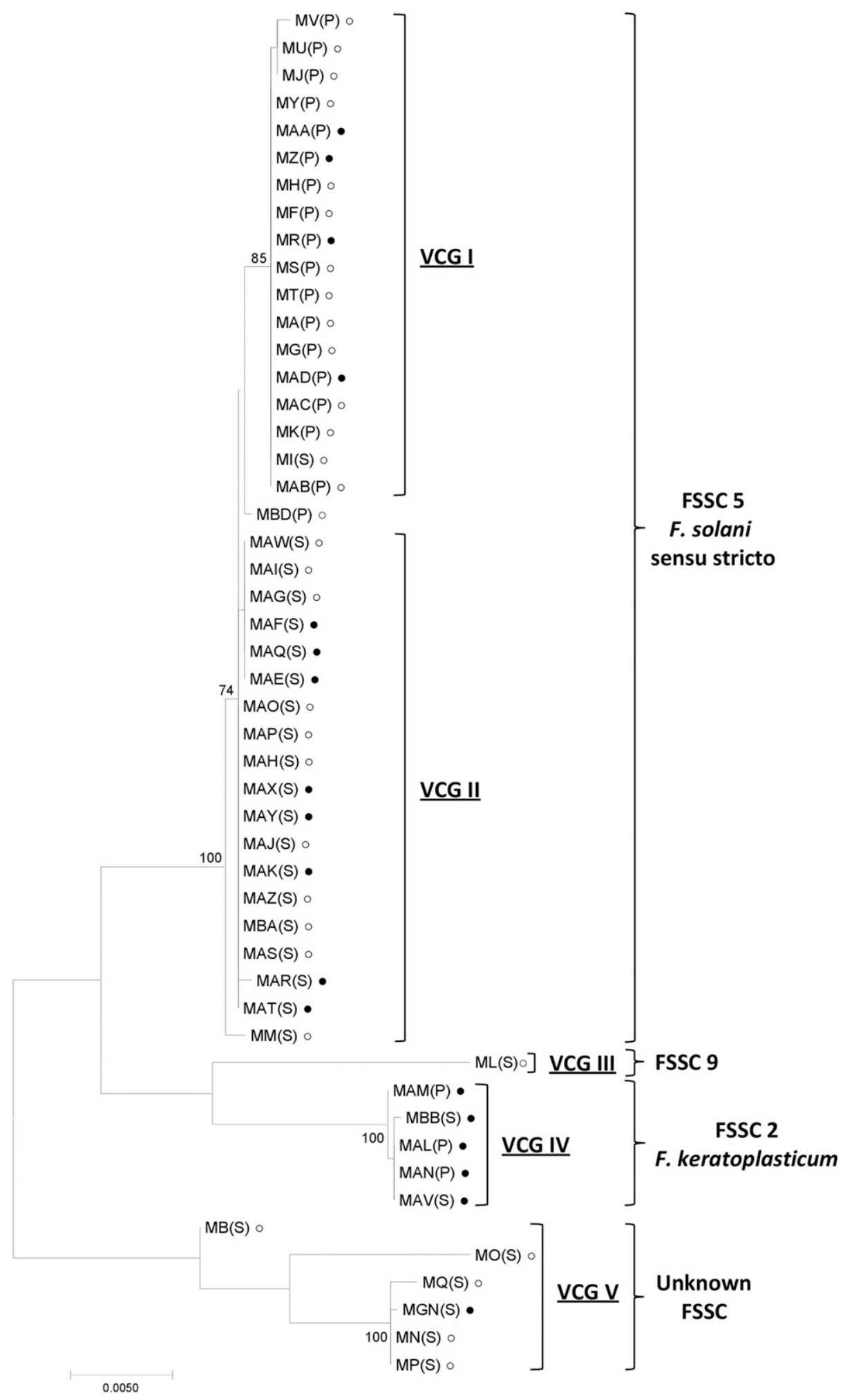

Fig. 2. Phylogenetic tree and vegetative compatibility groups (VCGs) inferred from Fusarium solani species complex (FSSC) isolates from soil (S) and strawberry plants $(\mathrm{P})$ from strawberry nurseries in the north-central region of Spain. Phylogenetic analysis was conducted by maximum likelihood analysis of the concatenated elongation factor- $1 \alpha$, internal transcribed spacer + large subunit, and RNA polymerase II loci. Bootstrap support values of $\geq 70 \%$ are indicated above branches. VCGs were determined using nitrate nonutilizing mutants as described by Jacobson and Gordon (1988). •, Pathogenic isolates; $\bigcirc$, nonpathogenic isolates. 
strawberry, and it was from soil origin (Fig. 2). The main pathogenic species detected in fruit production fields were FSSC 2, FSSC $3+4$, and FSSC 5, which contained 29, 67, and 57\% of pathogenic isolates from soil and plant origin, respectively. FSSC 11 was composed of a single plant isolate pathogenic to strawberry. All isolates in FSSC 6 were from soil origin and nonpathogenic to strawberry (Fig. 3). No relationship was observed between pathogenicity and the isolation source of isolates (soil or plant).

Genetic diversity. Haplotype analysis showed that the 100 FSSC isolates were distributed among 47 haplotypes (17 from

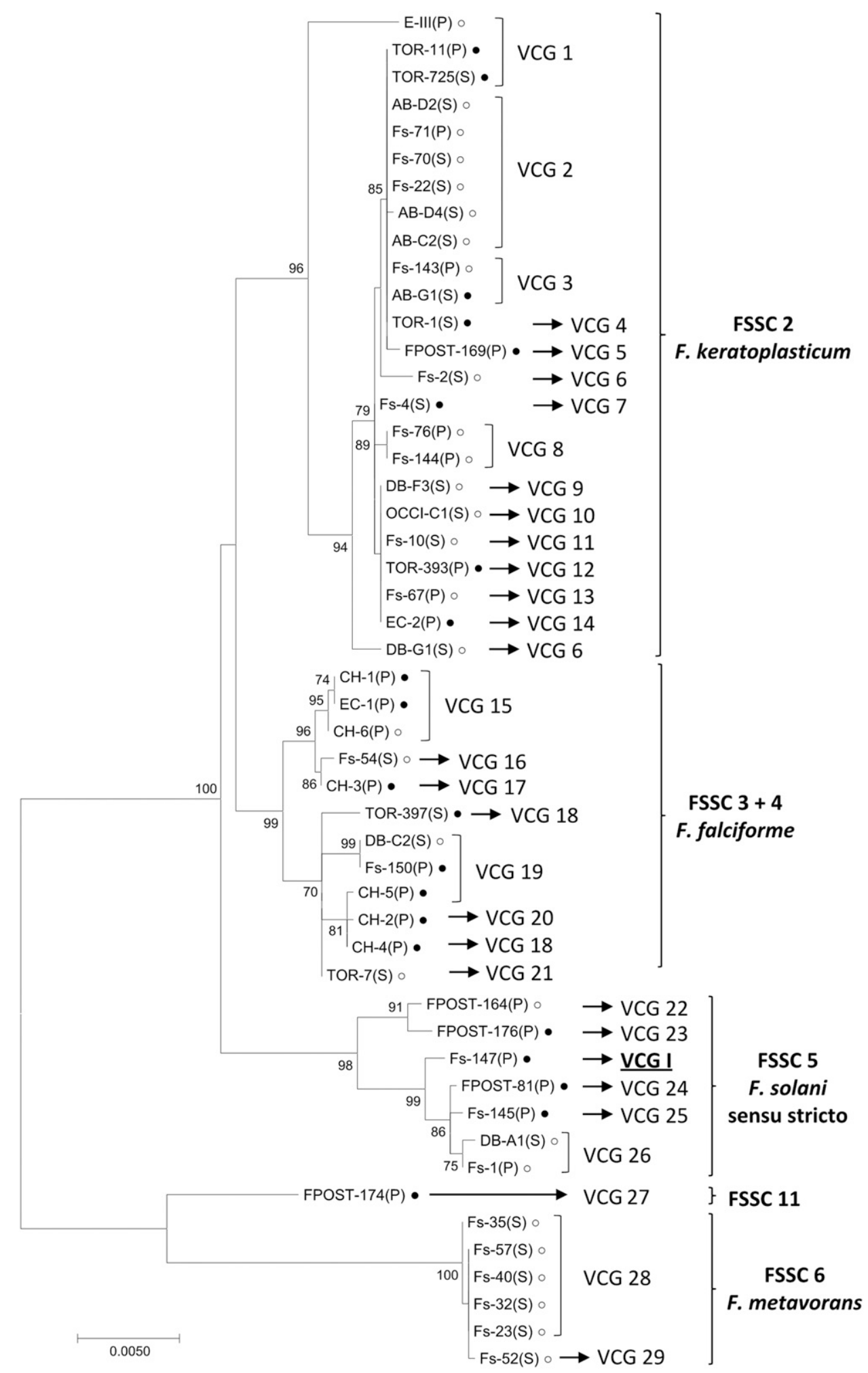

Fig. 3. Phylogenetic tree and vegetative compatibility groups (VCGs) inferred from Fusarium solani species complex (FSSC) isolates from soil (S) and strawberry plants (P) from strawberry fruit production fields from the southwestern region of Spain. Phylogenetic analysis was conducted by maximum likelihood analysis of the concatenated elongation factor- $1 \alpha$, internal transcribed spacer + large subunit, and RNA polymerase II loci. Bootstrap support values of $\geq 70 \%$ are indicated above branches. VCGs were determined using nitrate nonutilizing mutants as described by Jacobson and Gordon (1988). Underlined VCG corresponds to nursery compatibility group I. $\bullet$, Pathogenic isolates; $\bigcirc$, nonpathogenic isolates. 
nurseries and 30 from fruit production fields). No haplotypes were shared between nurseries and fruit production fields. The distribution of haplotypes was strongly tailed. Eleven unique multilocus haplotypes (singletons) were observed in nurseries, and 24 were observed in fruit production fields (Fig. 4). Some isolates from plants and soil shared the same haplotype: the most prevalent haplotype (H1) was detected in nurseries and contained isolates recovered from diseased plants (14 isolates) and soil (1 isolate). Haplotype $\mathrm{H} 4$ from nurseries and haplotypes H18, H19, and H21 from fruit production fields were also composed of isolates recovered from both soil and diseased plants (Fig. 4).

Genetic diversity was analyzed for the FSSC species detected in the two strawberry production areas using multilocus analyses (Table 2). Except for FSSC 6, all species in fruit production fields showed higher genetic diversity (haplotype and nucleotide diversity) than those from nurseries. The unknown FSSC from nurseries and FSSC 5 and FSSC $3+4$ from fruit production fields were the FSSC species with higher genetic diversity, showing the highest values of haplotype and nucleotide diversity.

Measures of genetic differentiation of FSSC 2 and FSSC 5 species between nurseries and fruit production fields based on DNA sequence polymorphisms indicated that mean diversity was higher between (Dxy) than within $(\pi)$ the preassigned production populations. Fst values for both FSSC species suggested low gene flow $(\mathrm{Nm}<1)$ between nurseries and fruit production fields. Finally, Snn values are close to one with large significance (Table 3). In all, these results indicate that the FSSC 2 and FSSC 5 species at the two production areas are highly differentiated populations.
VCGs. Phylogenetic analysis of the nursery isolates using the concatenated sequences allowed the 50 isolates to be categorized into five phylogenetic groups that correlated with five VCGs based on complementation tests involving nit mutants (Fig. 2). FSSC 5 was composed of two well-supported groups corresponding to VCG I (mostly plant isolates) and VCG II (exclusively composed of soil isolates). FSSC 9, composed of a soil isolate (ML), was the unique component of VCG III. FSSC 2 species, composed of plant and soil isolates, formed a well-supported group corresponding to VCG IV. The unknown FSSC species, exclusively composed of soil isolates, formed VCG V (Fig. 2). A good relationship was found between phylogenetic groups and VCGs in nurseries. No relationship was observed between VCG and the source of the isolates (soil or plant).

Phylogenetic analysis of the 50 isolates from fruit production fields rendered five phylogenetic species that did not correlated with VCGs. A total of 29 VCGs were inferred from the fruit production field isolates collected; however, most of them (20) were composed of a single isolate (Fig. 3). The rest (VCG 1, VCG 2, VCG 3 , VCG 19, and VCG 26) were composed of both soil and plant isolates, and VCG 6, VCG 8, VCG 15, and VCG 28 were exclusively plant or soil isolates. No relationship was observed between phylogenetic species and VCGs or between phylogenetic species and the isolates source (plant or soil) in the fruit production fields.

Most of VCGs were composed of both pathogenic and nonpathogenic isolates. Anastomosis between nursery and fruit production field isolates was only detected between pathogenic and nonpathogenic nursery isolates within VCG I and one

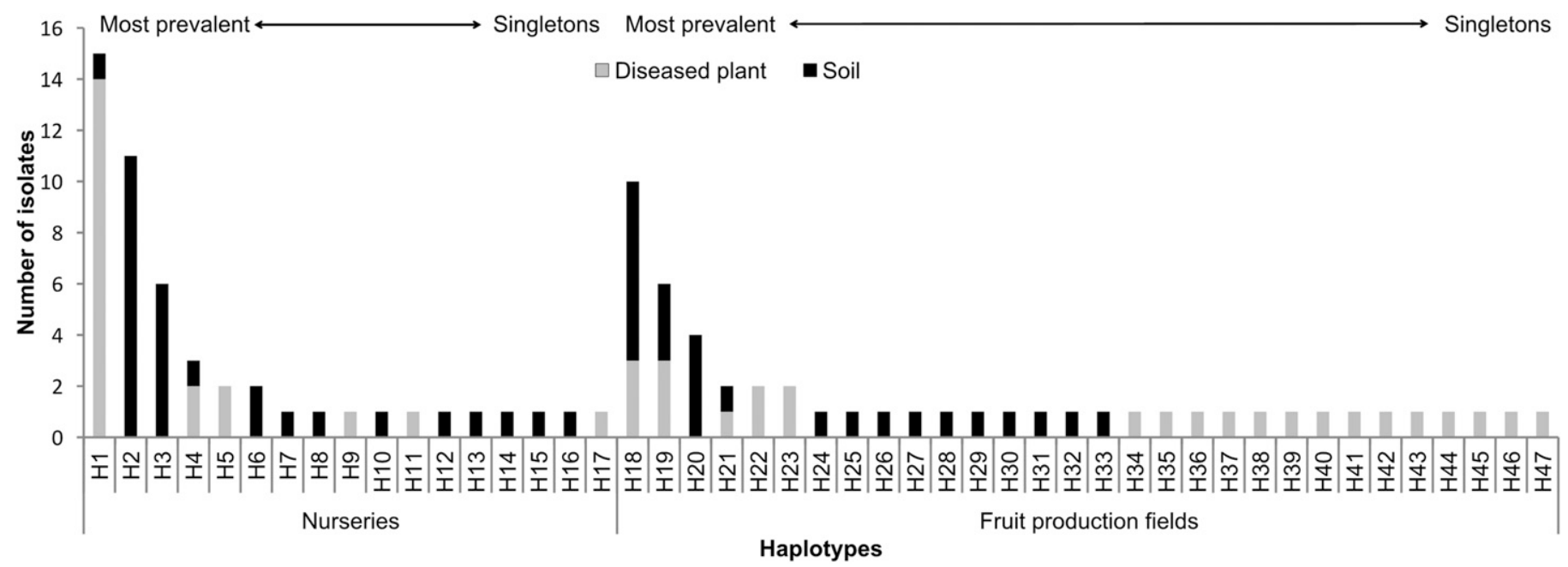

Fig. 4. Histogram showing the distribution of Fusarium solani species complex isolates from diseased plants and soil from Spanish strawberry nurseries and fruit production fields defined as number of isolates per multilocus haplotype.

TABLE 2. Fusarium solani species complex (FSSC) species detected in strawberry nurseries and fruit production fields and estimation of genetic diversity parameters by multilocus analysis of elongation factor- $1 \alpha$, internal transcribed spacer + large subunit, and RNA polymerase II

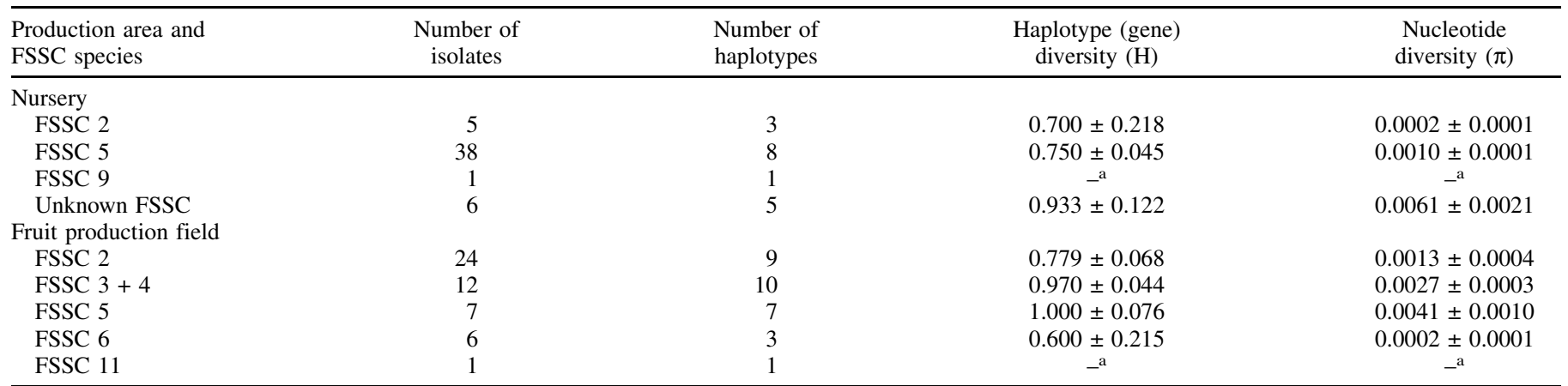

${ }^{a}$ Haplotype and nucleotide diversity were not calculated for species composed of a single isolate. 
pathogenic isolate (Fs-147P) from fruit production fields, all of them within the FSSC 5 species.

\section{DISCUSSION}

Here, we have identified the species of FSSC present in diseased plants and soils from the two Spanish strawberry production areas (plant nurseries located in the north-central region of the country and fruit production fields in the southwestern region), determined the genetic diversity and the structure of the strawberry-associated FSSC populations, and assessed the vegetative compatibility among isolates. An accurate molecular identification of the isolates was performed by MLST using the Fusarium MLST online database. Identification of Fusarium species has been traditionally based on morphological characteristics. However, morphology is not always enough to characterize some Fusarium species to the species level as demonstrated in previous morphological characterization of these isolates (Villarino et al. 2019). A complementary multilocus analysis allows Fusarium spp. to be more accurately identified (O'Donnell et al. 2015).

Six phylogenetic species of the FSSC were identified: that is, FSSC 2 (F. keratoplasticum), FSSC $3+4$ (F. falciforme), FSSC 5 ( $F$. solani sensu stricto), FSSC 6 ( $F$. metavorans sp. nov.), the unnamed phylogenetic species FSSC 9, and FSSC 11. An unknown FSSC species was also detected in the Spanish strawberry crop. All were nested within clade 3 of FSSC. There were differences in species composition and frequencies between the two production areas, with FSSC 5 and FSSC 2 being the most abundant species in nurseries and fruit production fields, respectively, and the only two species present in both areas. The rest of species were exclusive of nurseries (FSSC 9 and the unknown FSSC species) or fruit production fields (FSSC $3+4$, FSSC 6, and FSSC 11). The identification of multiple species of FSSC associated with strawberry supports the high diversity reported for this fungus (Coleman 2016) and accurately identified isolates that were previously designated as $F$. solani. The difference in the species composition suggests different origins of isolates in nurseries and fruit production fields, supporting similar results derived from morphological and pathogenic characterization of these isolates in earlier studies. Colony color and production of macroconidia were different for isolates from nurseries and fruit production fields; in addition, most severely pathogenic isolates came from diseased plants from fruit production fields, and less severe isolates came mainly from nursery soil (Villarino et al. 2019). Differences in species composition may also be owing to differences in crop management, geography, and soil composition. Although the same phytosanitary treatments are applied in nurseries and fruit production fields, the strawberry production type (runner plant or fruit), the climate, and the soil composition may be different in both production areas, which may influence the composition of the microbiota and hence, soilborne pathogenic fungi.

Among the most abundant species, FSSC $3+4$ from fruit production fields and FSSC 2 and FSSC 5 from both production areas showed the greatest percentages of pathogenic isolates. These strawberry-associated FSSC species have previously been described as pathogens to other crops, such as potato, soybean, and bean (Chehri et al. 2014; Chitrampalam and Nelson 2016; Sousa et al. 2017). They have also been associated with human infectious diseases (Al-Hatmi et al. 2018; Edupuganti et al. 2011; Short et al. 2013), supporting that agronomical and clinical members of FSSC share a common evolutionary origin as previously described (Zhang et al. 2006). The strawberry FSSC 11 consisted of a single isolate, FPOST-174P, pathogenic to strawberry. This isolate strongly nested with $F$. solani f. sp. pisi within FSSC 11 in the phylogenetic analysis. Components of FSSC 11 have been described as important root pathogens of soybean, dry bean, pea, and lentil (Chitrampalam and Nelson 2016). Based on their phylogenetic relationships, pathogenic isolates associated with strawberry could infect not only strawberry but other crops as described for some strawberryassociated $F$. solani isolates, which show a broad range of hosts and have the ability to infect tomato, garlic, and asparagus crops (Pastrana et al. 2017). Finally, one of six isolates within the unknown FSSC species was pathogenic to strawberry. The unknown FSSC species from nursery formed an independent VCG that did not associate with any of the previously described species included in the analysis, and it consistently formed an independent group with strong bootstrap support. The Fusarium MLST analysis of $E F-1 \alpha$, ITS, 28S, and RPB2 sequences from these unclassified isolates revealed association with multiple species: that is, FSSC 5 (for $E F-1 \alpha$ and $R P B 2$ sequences), FSSC $3+4$ (for ITS), and FSSC 34 (for 28S; data not shown). A detailed study of the morphological characteristics of these undescribed isolates or the study of additional genomic loci would be necessary to obtain a better identification and classification.

Among nonpathogenic species, members of FSSC 9 and FSSC 6 were previously described as frequent agents of human opportunistic infections (Homa et al. 2018; Tupaki-Sreepurna et al. 2017). In this work, these species were detected in nursery and fruit production field soil, respectively, and they could be a component of the saprophytic microbiota.

No relationship was detected between pathogenicity and the source (soil or plant) of the isolates. Because soil has been suggested as a reservoir of $F$. solani isolates and owing to the long-time survival of this fungus in the soil, strategies to reduce the level of inoculum in production soils, such as biosolarizarion, are of great importance and have been successfully implemented in Spanish strawberry fruit production areas (De la Lastra et al. 2018).

A correlation between VCGs and phylogenetic groups was observed in nursery, making vegetative compatibility a good marker for phylogenetic species identification in this area. However, in fruit production fields, phylogenetic groups are unable to distinguish all of the defined 29 VCGs. VCGs represent good phenotypic characteristics for assessing diversity within populations, but genetic relationships among VCGs are not always resolved by phylogenetic analyses (Maryani et al. 2019). The higher extent of variation revealed from VCGs in fruit production fields supports the higher genetic diversity (haplotype and nucleotide diversity) for the species detected in this area compared with nurseries. This could be because of multiple introductions of FSSC in strawberry fruit production areas. In fact, strawberry runner plants transplanted in fruit production fields come not only from Spanish nurseries but also, from other plant-growing countries (e.g., The Netherlands, Poland, and the United States). Strawberry cultivation as a monoculture in the southwestern region of Spain rules out the possibility of increased variability in this area owing to isolates from rotational crops. Another factor that could contribute to differences in diversity between the two production areas is the higher number of locations sampled in fruit production fields compared with nurseries. This is owing to the scenario of strawberry production in Spain, with a higher number of small plantations in the southwestern region that contrasts with a smaller number of more extensive and probably more homogeneous nurseries in the north-central region.

TABLE 3. Genetic differentiation parameters of Fusarium solani species complex 2 (FSSC 2) and FSSC 5 species between nurseries and fruit production fields

\begin{tabular}{lccccc}
\hline FSSC species & Dxy $^{\mathrm{a}}$ & Fst $^{\mathrm{b}}$ & $\mathrm{Nm}^{\mathrm{c}}$ & $\mathrm{Snn}^{\mathrm{d}}$ & $P$ value of Snn \\
\hline FSSC 2 & $0.0015 \pm 0.0006$ & 0.2518 & 0.74 & 0.9655 & 0.0000 \\
FSSC 5 & $0.0035 \pm 0.0011$ & 0.2744 & 0.66 & 0.9778 & 0.0000 \\
\hline
\end{tabular}

a Genetic diversity between populations (Nei 1987).

b Sequence-based statistic for genetic differentiation (Hudson et al. 1992).

c Estimation of gene flow (Hudson 2000).

d Nearest neighbor statistic for genetic differentiation (Hudson 2000).

e Significance of the nearest neighbor statistic for genetic differentiation value (Hudson et al. 1992). 
Infected propagative plant material has been suggested to be a potential source of inoculum of fungal pathogens, such as Colletotrichum acutatum (Ureña-Padilla et al. 2001), Phytophthora cactorum (Browne and Bhat 2011), and Botrytis cinerea (Oliveira et al. 2017) in strawberry-producing regions. In our study, we detected phylogenetic species, including pathogenic isolates, that were present in both nurseries and fruit production fields. However, analysis of the genetic differentiation between nurseries and fruit production fields for the only two species present in both strawberry production areas (i.e., FSSC 2 and FSSC 5) showed a low migration rate between both areas and indicated that populations in nurseries and fruit production fields were highly differentiated. Vegetative compatibility analysis supports these findings. Except for an anastomosis phenomenon within FSSC 5 species, vegetative compatibility between isolates from nurseries and fruit production fields was scarce. Anastomosis generally only takes place among strains with similar genotypes, supporting the genetic differentiation of isolates between the two strawberry production areas.

MLST and phylogenetic analyses of combined partial sequences of $E F-1 \alpha$, ITS + LSU, and RPB2 in this study have shown to be useful markers for identification and characterization of species in FSSC in strawberry crops. In addition, vegetative compatibility has been demonstrated to be another source of variability in FSSC. This information is important to understand the diversity and distribution of this complex species along Spanish strawberry production areas, and it could also be immensely useful for developing integrated disease management strategies.

\section{ACKNOWLEDGMENTS}

We thank M. C. Sánchez, R. Castillo, Y. Herranz, and B. Larena for technical assistance.

\section{LITERATURE CITED}

Al-Hatmi, A. M. S., Ahmed, S. A., van Diepeningen, A. D., Drogari-Apiranthitou, M., Verweij, P. E., Meis, J. F., and de Hoog, G. S. 2018. Fusarium metavorans sp nov.: The frequent opportunist 'FSSC6'. Med. Mycol. 56:S144-S152.

Aoki, T., O'Donnell, K., Homma, Y., and Lattanzi, A. 2003. Sudden-death syndrome of soybean is caused by two morphologically and phylogenetically distinct species within the Fusarium solani species complex-F-virguliforme in North America and F-tucumaniae in South America. Mycologia 95: 660-684

Ayoubi, N., and Soleimani, M. J. 2016. Morphological and molecular identification of pathogenic Fusarium spp. on strawberry in Iran. Sydowia 68: 163-171.

Browne, G. T., and Bhat, R. G. 2011. Pages 1-4 in: Phytophthora Crown and Root Rot. California Strawberry Commission, Watsonville, CA.

Ceja-Torres, L. F., Mora-Aguilera, G., Teliz, D., Mora-Aguilera, A., Sánchez-García, P., Muñoz-Ruiz, C., Tlapal-Bolanos, B., and De la Torre-Almaraz, R. 2008. Fungi prevalence and etiology of strawberry dry wilt under different crop management systems. Agrociencia 42:451-461.

Chehri, K., Ghasempour, H., and Karimi, N. 2014. Molecular phylogenetic and pathogenetic characterization of Fusarium solani species complex (FSSC), the cause of dry rot on potato in Iran. Microb. Pathog. 67-68:14-19.

Chitrampalam, P., and Nelson, B. 2016. Multilocus phylogeny reveals an association of agriculturally important Fusarium solani species complex (FSSC) 11, and clinically important FSSC 5 and FSSC 3+4 with soybean roots in the north central United States. Antonie Van Leeuwenhoek Int. J. Gen. Mol. Microbiol. 109:335-347.

Coleman, J. J. 2016. The Fusarium solani species complex: Ubiquitous pathogens of agricultural importance. Mol. Plant Pathol. 17:146-158.

De Cal, A., Martínez-Treceno, A., López-Aranda, J. M., and Melgarejo, P. 2004. Chemical alternatives to methyl bromide in Spanish strawberry nurseries. Plant Dis. 88:210-214.

De la Lastra, E., Basallote-Ureba, M. J., De los Santos, B., Miranda, L., Dolores Vela-Delgado, M., and Capote, N. 2018. A TaqMan real-time polymerase chain reaction assay for accurate detection and quantification of Fusarium solani in strawberry plants and soil. Sci. Hortic. 237:128-134.

Edgar, R. C. 2004. MUSCLE: Multiple sequence alignment with high accuracy and high throughput. Nucleic Acids Res. 32:1792-1797.

Edupuganti, S., Rouphael, N., Mehta, A., Eaton, M., Heller, J., Bressler, A., Brandt, M., and O'Donnell, K. 2011. Fusarium falciforme vertebral abscess and osteomyelitis: Case report and molecular classification. J. Clin. Microbiol. 49:2350-2353

FAOSTAT. 2016. Food and Agriculture Organization of the United Nations. http://www.fao.org/home/en/

Homa, M., Galgoczy, L., Manikandan, P., Narendran, V., Sinka, R., Csernetics, A., Vagvolgyi, C., Kredics, L., and Papp, T. 2018. South Indian isolates of the Fusarium solani species complex from clinical and environmental samples: Identification, antifungal susceptibilities, and virulence. Front. Microbiol. 9:1052.

Hudson, R. R. 2000. A new statistic for detecting genetic differentiation. Genetics 155:2011-2014.

Hudson, R. R., Boos, D. D., and Kaplan, N. L. 1992. A statistical test for detecting geographic subdivision. Mol. Biol. Evol. 9:138-151.

Jacobson, D. J., and Gordon, T. R. 1988. Vegetative compatibility and selfincompatibility within Fusarium oxysporum f. sp. melonis. Phytopathology 78:668-672.

Kumar, S., Stecher, G., and Tamura, K. 2016. MEGA7: Molecular Evolutionary Genetics Analysis Version 7.0 for bigger datasets. Mol. Biol. Evol. 33:1870-1874.

Leslie, J. F. 1993. Fungal vegetative compatibility. Annu. Rev. Phytopathol. $31: 127-150$

Leslie, J. F., and Summerell, B. A. 2006. The Fusarium Laboratory Manual. Blackwell Publishing, Ames, IA.

Librado, P., and Rozas, J. 2009. DnaSP v5: A software for comprehensive analysis of DNA polymorphism data. Bioinformatics 25:1451-1452.

López-Aranda, J. M. 2008. El cultivo de la fresa en Huelva. Pages 103-172 in: La fresa de Huelva. Ed. Junta de Andalucía. Consejería de Agricultura y Pesca, Sevilla, Spain.

Manici, L. M., Caputo, F., and Baruzzi, G. 2005. Additional experiences to elucidate the microbial component of soil suppressiveness towards strawberry black root rot complex. Ann. Appl. Biol. 146:421-431.

Martin, F. N. 2003. Development of alternative strategies for management of soilborne pathogens currently controlled with methyl bromide. Annu. Rev. Phytopathol. 41:325-350.

Maryani, N., Lombard, L., Poerba, Y. S., Subandiyah, S., Crous, P. W., and Kema, G. H. J. 2019. Phylogeny and genetic diversity of the banana Fusarium wilt pathogen Fusarium oxysporum f. sp. cubense in the Indonesian centre of origin. Stud. Mycol. 92:155-194.

Mehmood, N., Riaz, A., Jabeen, N., Anwaar, S., Hussain, S., Abbas, M., Zhang, X., Rosli, H., and Gleason, M. 2017. First report of Fusarium solani causing fruit rot of strawberry in Pakistan. Plant Dis. 101:1681.

Mirmajlessi, S. M., Bahram, M., Mand, M., Najdabbasi, N., Mansouripour, S., and Loit, E. 2018. Survey of soil fungal communities in strawberry fields by Illumina amplicon sequencing. Eurasian Soil Sci. 51:682-691.

Molinero-Ruiz, L., Rubio-Pérez, E., González-Domínguez, E., and Basallote-Ureba, M. J. 2011. Alternative hosts for Fusarium spp. causing crown and root rot of asparagus in Spain. J. Phytopathol. 159: 114-116.

Nalim, F. A., Samuels, G. J., Wijesundera, R. L., and Geiser, D. M. 2011. New species from the Fusarium solani species complex derived from perithecia and soil in the Old World tropics. Mycologia 103:1302-1330.

Nei, M. 1987. Molecular Evolutionary Genetics. Columbia University Press, New York.

O'Donnell, K. 2000. Molecular phylogeny of the Nectria haematococcaFusarium solani species complex. Mycologia 92:919-938.

O’Donnell, K., Cigelnik, E., and Nirenberg, H. I. 1998a. Molecular systematics and phylogeography of the Gibberella fujikuroi species complex. Mycologia 90:465-493.

O’Donnell, K., Kistler, H. C., Cigelnik, E., and Ploetz, R. C. 1998b. Multiple evolutionary origins of the fungus causing Panama disease of banana: Concordant evidence from nuclear and mitochondrial gene genealogies. Proc. Natl. Acad. Sci. USA 95:2044-2049.

O'Donnell, K., Sutton, D. A., Fothergill, A., McCarthy, D., Rinaldi, M. G., Brandt, M. E., Zhang, N., and Geiser, D. M. 2008. Molecular phylogenetic diversity, multilocus haplotype nomenclature, and in vitro antifungal resistance within the Fusarium solani species complex. J. Clin. Microbiol. 46: 2477-2490.

O’Donnell, K., Sutton, D., Rinaldi, M., Sarver, B., Balajee, S., Schroers, H., Summerbell, R., Robert, V., Crous, P., Zhang, N., Aoki, T., Jung, K., Park, J., Lee, Y., Kang, S., Park, B., and Geiser, D. 2010. Internet-accessible DNA sequence database for identifying fusaria from human and animal infections. J. Clin. Microbiol. 48:3708-3718.

O’Donnell, K., Ward, T. J., Robert, V. A. R. G., Crous, P. W., Geiser, D. M., and Kang, S. 2015. DNA sequence-based identification of Fusarium: Current status and future directions. Phytoparasitica 43:583-595.

Oliveira, M. S., Amiri, A., Zuniga, A. I., and Peres, N. A. 2017. Sources of primary inoculum of Botrytis cinerea and their impact on fungicide resistance development in commercial strawberry fields. Plant Dis. 101: 1761-1768. 
Pastrana, A., Capote, N., De los Santos, B., Romero, F., and Basallote-Ureba, M. J. 2014. First report of Fusarium solani causing crown and root rot on strawberry crops in southwestern Spain. Plant Dis. 98:161.

Pastrana, A. M., Basallote-Ureba, M. J., and Capote, N. 2017. Symptomless reservoirs of Fusarium oxysporum f. sp. fragariae and alternative hosts of Fusarium solani pathogenic to strawberry. J. Plant Pathol. 99:141-148.

Puhalla, J. E. 1985. Classification of strains of Fusarium oxysporum on the basis of vegetative compatibility. Can. J. Botany-Revue Can. De Bot. 63:179-183.

Redondo, C., Villarino, M., Larena, I., Melgarejo, P., and De Cal, A. 2012. Enfermedades emergentes en los viveros de altura de fresa tras la retirada del bromuro de metilo en 2009. XVI Congreso Nacional de la Sociedad Española de Fitopatología. Málaga, Spain.

Schippers, B., and van Eck, W. H. 1981. Formation and survival of chlamydospores in Fusarium. Pages 250-260 in: Fusarium: Diseases, Biology, and Taxonomy. P. E. Nelson, T. A. Toussoun, and R. J. Cook, eds. Penn. State Univ. Press, University Park.

Schroers, H. J., Samuels, G. J., Zhang, N., Short, D. P. G., Juba, J., and Geiser, D. M. 2016. Epitypification of Fusisporium (Fusarium) solani and its assignment to a common phylogenetic species in the Fusarium solani species complex. Mycologia 108:806-819.

Shoemaker, J. S., and Fitch, W. M. 1989. Evidence from nuclear sequences that invariable sites should be considered when sequence divergence is calculated. Mol. Biol. Evol. 6:270-289.

Short, D. P. G., O’Donnell, K., Thrane, U., Nielsen, K. F., Zhang, N., Juba, J. H., and Geiser, D. M. 2013. Phylogenetic relationships among members of the Fusarium solani species complex in human infections and the descriptions of $F$. keratoplasticum sp. nov. and $F$. petroliphilum stat. nov. Fungal Genet. Biol. 53:59-70.

Sousa, E. S., Melo, M. P., Mota, J. M., Sousa, E. M. J., Beserra, J. E. A., and Matos, K. S. 2017. First report of Fusarium falciforme (FSSC 3+4) causing root rot in lima bean (Phaseolus lunatus L.) in Brazil. Plant Dis. 101:1954.

Sugimoto, M., Koike, M., Nagao, H., Okumura, K., Tani, M., and Kuramochi, K. 2003. Genetic diversity of the entomopathogen Verticillium lecanii on the basis of vegetative compatibility. Phytoparasitica 31:450-457.

Summerbell, R., and Schroers, H. 2002. Analysis of phylogenetic relationship of Cylindrocarpon lichenicola and Acremonium falciforme to the Fusarium solani species complex and a review of similarities in the spectrum of opportunistic infections caused by these fungi. J. Clin. Microbiol. 40: 2866-2875.

Swift, C. E., Wickliffe, E. R., and Schwartz, H. F. 2002. Vegetative compatibility groups of Fusarium oxysporum f. sp cepae from onion in Colorado. Plant Dis. 86:606-610.

Tamura, K., and Nei, M. 1993. Estimation of the number of nucleotide substitutions in the control region of mitochondrial-DNA in humans and chimpanzees. Mol. Biol. Evol. 10:512-526.

Tavaré, S. 1986. Some probabilistic and statistical problems in the analysis of DNA sequences. Pages 57-86 in: Some Mathematical Questions in Biology-DNA Sequence Analysis. R. M. Miura, ed. American Mathematical Society, Providence, RI.

Thompson, J. D., Higgins, D. G., and Gibson, T. J. 1994. Clustal-W: Improving the sensitivity of progressive multiple sequence alignment through sequence weighting, position-specific gap penalties and weight matrix choice. Nucleic Acids Res. 22:4673-4680.

Tupaki-Sreepurna, A., Al-Hatmi, A., Kindo, A., Sundaram, M., and de Hoog, G. 2017. Multidrug-resistant Fusarium in keratitis: A clinico-mycological study of keratitis infections in Chennai, India. Mycoses 60:230-233.

Ureña-Padilla, A. R., Mitchell, D. J., and Legard, D. E. 2001. Oversummer survival of inoculum for Colletotrichum crown rot in buried strawberry crown tissue. Plant Dis. 85:750-754.

Villarino, M., De la Lastra, E., Basallote-Ureba, M. J., Capote, N., Larena, I., Melgarejo, P., and De Cal, A. 2019. Characterization of Fusarium solani populations associated with Spanish strawberry crops. Plant Dis. 103: 1974-1982.

White, T. J., Bruns, T., Lee, S., and Taylor, J. 1990. Amplification and direct sequencing of fungal ribosomal RNA genes for phylogenetics. Pages 315-322 in: PCR Protocols: A Guide to Methods and Applications. M. A. Innis, D. H Gelfand, J. J. Sninsky, and T. J. White, eds. Academic Press, San Diego, CA.

Yang, Z. H. 1994. Maximum-likelihood phylogenetic estimation from DNAsequences with variable rates over sites-approximate methods. J. Mol. Evol. 39:306-314

Zhang, N., O'Donnell, K., Sutton, D. A., Nalim, F. A., Summerbell, R. C., Padhye, A. A., and Geiser, D. M. 2006. Members of the Fusarium solani species complex that cause infections in both humans and plants are common in the environment. J. Clin. Microbiol. 44:2186-2190. 